\title{
Infestação de plantas daninhas de difícil controle em função de anos de consórcio milho-braquiária
}

\author{
Ivan Arcanjo Mechi ${ }^{1}$, Anna Luiza Farias dos Santos ${ }^{1}$, Luan Marlon Ribeiro ${ }^{1}$, Gessí Ceccon ${ }^{2}$ \\ ${ }^{1}$ Universidade Federal da Grande Dourados, Dourados, Mato Grosso do Sul, Brasil. E-mail: ivarmec@ @otmail.com, \\ annaluiza_di@hotmail.com, luanmarlon@hotmail.com
}

${ }^{2}$ Empresa Brasileira de Pesquisa Agropecuária - Embrapa Agropecuária Oeste - CPAO, Dourados - MS, Brasil. E-mail: gessi.ceccon@embrapa.br

Recebido: 03/05/2017; Aceito: 02/05/2018.

\section{RESUMO}

Objetivou-se com esse trabalho avaliar a infestação de plantas daninhas após cinco anos de cultivo com milho solteiro ou consorciado com Brachiaria ruziziensis no outono-inverno. Os tratamentos foram estabelecidos em áreas com diferentes períodos de consórcio (milho+braquiária) e cultivos do milho solteiro entre 2011 a 2015, sendo milho solteiro de 2011 a 2015, consórcio em 2011 + milho solteiro de 2012 a 2015, consórcio em 2011 e 2012 + milho solteiro de 2013 a 2015, consórcio de 2011 a 2013 + milho solteiro em 2014 e 2015, consórcio de 2011 a 2014 + milho solteiro em 2015, consórcio de 2011 a 2015, milho solteiro em 2011 + consórcio de 2012 a 2015, milho solteiro em 2011 e 2012 + consórcio de 2013 a 2015, milho solteiro de 2011 a 2013 + consórcio em 2014 e 2015, milho solteiro de 2011 a $2014+$ consórcio em 2015. As maiores massas secas de Coniza spp. foram observadas nos tratamentos milho solteiro 2011 a 2015, consórcio 2011 e 2012 + milho solteiro 2013 a 2015 e consórcio 2011 a 2013 + milho solteiro 2014 e 2015 e de Digitaria spp. nos tratamentos milho solteiro 2011 a 2015, consórcio 2011 + milho solteiro 2012 a 2015 e consórcio 2011 e 2012 + milho solteiro 2013 a 2015. No ano de cultivo, o consórcio milho-braquiária aumenta a massa total de resíduos e inibe a presença de plantas daninhas. A reinfestação por Coniza spp. ocorre após um ano sem consórcio e de Digitaria spp. após dois anos sem consórcio, porém em menores quantidades do que na sucessão soja-milho safrinha.

Palavras-chave: Brachiaria ruziziensis, Coniza bonariensis, Digitaria insularis.

\section{Weed infestation of difficult control due to years of maize-ruzigrass intercrop}

\begin{abstract}
The objective of this study was to evaluate the infestation of weeds after five years of cultivation with single maize or intercropped with Brachiaria ruziziensis. The treatments were established in areas with different periods of intercrop (maize + B. ruziziensis) and single maize crop between 2011 and 2015, being single maize from 2011 to 2015, intercrop in $2011+$ single maize from 2012 to 2015, intercrop in 2011 and $2012+$ single maize from 2013 to 2015, intercrop from 2011 to 2013 + single maize in 2014 and 2015, intercrop from 2011 to 2014 + single maize in 2015, intercrop from 2011 to 2015, single maize in $2011+$ intercrop from 2012 to 2015, single maize in 2011 and 2012 + intercrop from 2013 to 2015, single maize from 2011 to 2013 + intercrop in 2014 and 2015, single maize from 2011 to $2014+$ intercrop in 2015. The highest dry mass of Coniza spp. were observed in treatments single maize from 2011 to 2015, intercrop in 2011 and 2012 + single maize from 2013 to 2015 and intercrop from 2011 to 2013 + single maize in 2014 and 2015 and of Digitaria spp. in the treatments single maize from 2011 to 2015, intercrop in 2011 + single maize from 2012 to 2015and intercrop in 2011 and 2012 + single maize from 2013 to 2015. In the year of its cultivation, the maize-B. ruziziensis intercrop increases the total mass of residues and inhibits the presence of weeds in the year of its cultivation. Reinfestation by Coniza spp. occurs after one year without intercrop and of Digitaria spp. after two years without intercrop.
\end{abstract}

Keywords: Brachiaria ruziziensis, Coniza bonariensis, Digitaria insularis. 


\section{Introdução}

O plantio direto consiste em um sistema que visa o não revolvimento do solo e, por consequência, a manutenção dos resíduos vegetais em cobertura e o aporte de material orgânico, porém, geralmente, não sendo suficiente a quantidade de resíduos deixados pelas culturas.

O milho solteiro, mesmo produzindo alta quantidade de massa seca de resíduos, não promove perfeita cobertura do solo. Isso, se deve ao fato, de sua massa seca estar em sua maior parte concentrada nos colmos e não nas folhas (Andrade, 1995).

Com a utilização do consórcio milho-braquiária no outono/inverno, se torna possível maximizar todos os benefícios do plantio direto, devido, principalmente, à elevada produção de resíduos de raízes e parte aérea por parte da forrageira, aumentando de forma significativa a área e tempo de solo coberto.

A chegada da tecnologia Roundup Ready no Brasil, principalmente com as sementes de soja e milho RR, induziu o aumento na utilização de herbicidas à base de glifosato (Malty et al., 2006). O seu uso de forma indiscriminada levou a uma seleção de plantas daninhas resistentes, em especial as espécies de Digitaria insularis e Coniza bonariensis. Com a dificuldade de controle químico, formas alternativas se tornam cada vez mais importantes, como exemplo, o controle cultural.

Em áreas onde não se utilizam plantas de cobertura, há um aumento considerável no banco de sementes de plantas infestantes, que serão produzidos na entressafra, devido, principalmente, à falta de cobertura nessa época de pousio. Com isso, a infestação de plantas daninhas na estação de cultivo subsequente tende a ser mais severa (Concenço et al., 2011).

A realização do presente trabalho teve como objetivo avaliar a infestação de plantas daninhas de difícil controle após anos de cultivo de milho solteiro ou consorciado com Brachiaria ruziziensis no outonoinverno.

\section{Material e Métodos}

O trabalho foi desenvolvido na área experimental da Embrapa Agropecuária Oeste, em Ponta Porã, MS, coordenadas $22^{\circ} 25^{\prime} \mathrm{S}$ e $55^{\circ} 32^{\prime} \mathrm{W}$ e altitude de $632 \mathrm{~m}$, em solo classificado como Latossolo Vermelho distrófico, de textura argilosa (Santos et al., 2013). O clima, segundo classificação de Köppen, é Subtropical Úmido, do tipo Cfa, com base nos dados do Guia Clima (Embrapa, 2016). Os dados pluviométricos e as temperaturas máximas e mínimas foram obtidos no Centro de Monitoramento de Tempo, do Clima e dos Recursos Hídricos de Mato Grosso do Sul (Figura 1).O delineamento experimental foi em blocos casualizados, em parcelas de 15 × $20 \mathrm{~m}$, quatro repetições e dez tratamentos, tendo em todas as parcelas o cultivo de soja no verão e de milho solteiro ou consorciado com Brachiaria ruziziensis no outono-inverno.

Os tratamentos foram estabelecidos em áreas com diferentes períodos de consórcio (milho+braquiária) e cultivos do milho solteiro entre 2011 a 2015, sendo eles milho solteiro de 2011 a 2015, consórcio em $2011+$ milho solteiro de 2012 a 2015, consórcio em 2011 e 2012 + milho solteiro de 2013 a 2015, consórcio de 2011 a 2013 + milho solteiro em 2014 e 2015, consórcio de 2011 a 2014 + milho solteiro em 2015, consórcio de 2011 a 2015, milho solteiro em 2011 + consórcio de 2012 a 2015, milho solteiro em 2011 e 2012 + consórcio de 2013 a 2015, milho solteiro de 2011 a 2013 + consórcio em 2014 e 2015, milho solteiro de 2011 a 2014 + consórcio em 2015.

$\mathrm{O}$ cultivo da soja antecessora à safrinha foi semelhante em todos os anos, sendo utilizada a cultivar BRS 1001IPRO, semeada trinta dias após a dessecação da braquiária da safrinha anterior, em linhas espaçadas em $0,45 \mathrm{~m}$, e população planejada de 300 mil plantas por hectare.

Em 2015 o milho, híbrido simples DKB 390 VT PRO, e a braquiária foram semeados em área total, de forma idêntica aos anos anteriores, sendo o milho com linhas espaçadas de $0,45 \mathrm{~m}$ e população de $50 \mathrm{mil}$ plantas por hectare e a B. ruziziensis à lanço, com 100 mil plantas por hectare. Nas parcelas de milho solteiro a braquiária foi eliminada com uma aplicação de gliphosate $1,44 \mathrm{~kg} \mathrm{ha}^{-1}$ com jato dirigido na entrelinha do milho, 15 dias após a emergência. Não houve a necessidade do uso de subdoses de gliphosate para controle da braquiária.

A adubação de semeadura no milho foi de $200 \mathrm{~kg}$ $\mathrm{ha}^{-1}$ da fórmula 08-20-20 NPK. Para o controle de lagartas foi aplicado o inseticida clorpirifós na dose de $240 \mathrm{~g} \mathrm{ha}^{-1}$ e para o controle de percevejos utilizou-se tiametoxam com lambda-cialotrina $\left(35+26 \mathrm{~g}\right.$ ha $\left.^{-1}\right)$. Foi realizada aplicação de atrazine na dose de $2,5 \mathrm{~kg} \mathrm{ha}^{-1}$ para controle de plantas daninhas.

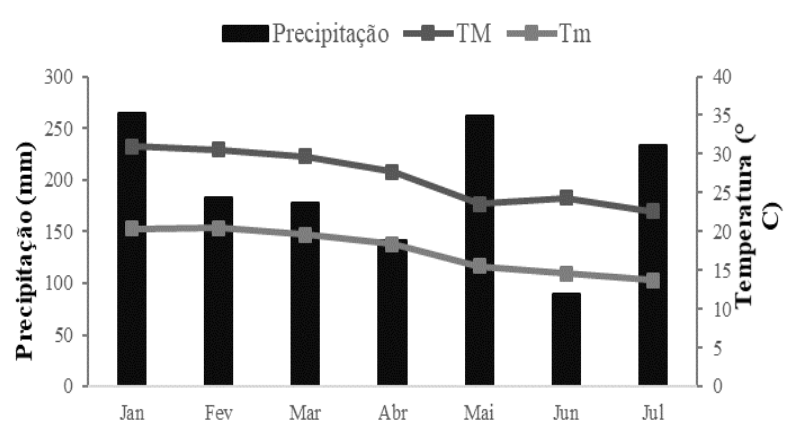

Figura 1. Média mensal da precipitação pluvial e temperaturas máximas e mínimas no período de janeiro a julho de 2015, Ponta Porã, MS. Fonte: CEMTEC. 
A colheita do milho foi realizada no dia 27 de julho de 2015. Após isso a braquiária foi mantida nos respectivos tratamentos consorciados e depois de quarenta e três dias, no dia 08 de setembro foi realizada a dessecação de pré-plantio da soja com gliphosate 1,44 $\mathrm{kg} \mathrm{ha}^{-1}$.

No dia 06 de outubro de 2015 foi realizada a coleta de plantas daninhas e de resíduos culturais, com auxílio de um quadrado de metal de $0,5 \times 0,5 \mathrm{~m}$, onde o mesmo foi arremessado aleatoriamente dentro de cada parcela e realizada a coleta dos resíduos presentes dentro da área do quadrado. Foram encontrados resíduos de milho e $B$. ruziziensis e plantas daninhas, com predominância de Digitaria insularis (capim amargoso) e Coniza bonariensis (buva). Após a coleta, as plantas foram separadas por espécie e levadas para secagem em estufa à temperatura constante de $60{ }^{\circ} \mathrm{C}$ durante dez dias.

Foram avaliadas as massas secas, em $\mathrm{kg} \mathrm{ha}^{-1}$, de milho, B. ruziziensis, buva, capim amargoso, a somatória de buva e capim amargoso e a massa seca total, correspondente ao somatório das massas secas das culturas e plantas daninhas. Além disso, foi avaliado o número de plantas por hectare para buva, capim amargoso e o somatório de buva e capim amargoso. Os resultados foram submetidos à análise de variância e as médias comparadas pelo teste de Scott-Knott a 5\% de probabilidade.

\section{Resultados e Discussão}

A análise de variância detectou efeito significativo dos tratamentos (anos de consórcio milho-braquiária) sobre todas as variáveis analisadas. As maiores massas secas de resíduos de milho foram observadas nos tratamentos com milho solteiro em 2015, cultivados após três (consórcio de 2011 a 2013 + milho solteiro em 2014 e 2015) e quatro (consórcio de 2011 a $2014+$ milho solteiro em 2015) anos de consórcio, superando os tratamentos onde o milho esteve sempre solteiro (testemunha- milho solteiro de 2011 a 2015) e sempre consorciado (consórcio de 2011 a 2015) (Tabela 1).

Nos tratamentos consórcio de 2011 a $2013+$ milho solteiro em 2014 e 2015 e consórcio de 2011 a $2014+$ milho solteiro em 2015 não havia o efeito competidor da braquiária consorciada com o milho no ano de avaliação, porém existia o efeito benéfico e residual da braquiária totalmente decomposta dos anos anteriores a 2015, o que provavelmente contribuiu com o melhor desenvolvimento das plantas de milho nesses dois tratamentos, apresentando dessa forma as maiores massas secas de resíduo de milho (Tabela 1).

Os tratamentos milho solteiro de 2011 a $2014+$ consórcio em 2015 e milho solteiro em 2011 e $2012+$ consórcio de 2013 a 2015 apresentaram as menores quantidades de massa seca de resíduo de milho (Tabela
1). No cultivo consorciado, geralmente não há interferência significativa da braquiária sobre o milho, porém quando a população da forrageira está elevada, o desenvolvimento das plantas de milho será afetado negativamente e a produção de massa do capim tende a ser favorecida (Ceccon et al., 2012).

Os tratamentos com presença da braquiária no ano de 2015 (consórcio de 2011 a 2015, milho solteiro em 2011 + consórcio de 2012 a 2015, milho solteiro em 2011 e 2012 + consórcio de 2013 a 2015, milho solteiro de 2011 a 2013 + consórcio em 2014 e 2015 e milho solteiro de 2011 a 2014 + consórcio em 2015) apresentaram as maiores massas secas de resíduo de braquiária e resíduo total, com média de $7.183 \mathrm{~kg} \mathrm{ha}^{-1}$ de massa seca total de resíduos deixados em cobertura, superando a média de $3.919 \mathrm{~kg} \mathrm{ha}^{-1}$ total de resíduos deixados em cobertura pelos tratamentos sem presença de braquiária em 2015 (milho solteiro de 2011 a 2015, consórcio em 2011 + milho solteiro de 2012 a 2015, consórcio em 2011 e 2012 + milho solteiro de 2013 a 2015, consórcio de 2011 a 2013 + milho solteiro em 2014 e 2015 e consórcio de 2011 a 2014 + milho solteiro em 2015) (Tabela 1).

Silva et al. (2011) afirmam que o sistema plantio direto, ao produzir e manter acima de 5 toneladas de palha sobre a superfície do solo, proporciona inúmeras melhorias ao sistema de produção, como a diminuição da densidade do solo, a melhor infiltração e retenção de água, favorece a aeração e o crescimento radicular das culturas, além de promover a manutenção da umidade do solo.

Os tratamentos consórcio em 2011 e $2012+$ milho solteiro de 2013 a 2015, consórcio de 2011 a $2013+$ milho solteiro em 2014 e 2015 e consórcio de 2011 a 2014 + milho solteiro em 2015, apesar de estarem cultivados com milho solteiro no ano de avaliação (2015), apresentaram resíduos de braquiária, com 101, 235 e $1.019 \mathrm{~kg} \mathrm{ha}^{-1}$, respectivamente, porém em menores quantidades do que os tratamentos consórcio de 2011 a 2015, milho solteiro em 2011 + consórcio de 2012 a 2015, milho solteiro em 2011 e 2012 + consórcio de 2013 a 2015, milho solteiro de 2011 a $2013+$ consórcio em 2014 e 2015 e milho solteiro de 2011 a 2014 + consórcio em 2015 (Tabela 1). Os resíduos de braquiária encontrados nesses três tratamentos se devem, provavelmente, à rebrota e às sementes produzidas pela forrageira cultivada nos anos anteriores a 2015.

Os tratamentos consorciados em 2015 (consórcio de 2011 a 2015, milho solteiro em 2011 + consórcio de 2012 a 2015, milho solteiro em 2011 e 2012 + consórcio de 2013 a 2015, milho solteiro de 2011 a $2013+$ consórcio em 2014 e 2015 e milho solteiro de 2011 a 2014 + consórcio em 2015) apresentaram ausência de plantas daninhas (Tabelas 2 e 3) devido à melhor 
cobertura do solo proporcionada pela braquiária, em especial na entressafra, período compreendido entre a colheita do milho no outono-inverno e a semeadura da safra de soja no verão, quando são produzidas as maiores quantidades de sementes de plantas invasoras. No consórcio de milho com braquiária, após realizar-se a colheita do milho, a braquiária se estabelece na área, proporcionando cobertura e proteção ao solo na época de pousio. Existem dois mecanismos principais de atuação da braquiária no controle de plantas daninhas. $\mathrm{O}$ primeiro está relacionado com a capacidade da forrageira em produzir substâncias alelopáticas, que por sua vez irão inibir diretamente o crescimento das invasoras ou estimularão fungos capazes de atacar o banco de sementes. O segundo mecanismo está relacionado com a barreira física proporcionada pela cobertura vegetal contra a incidência de raios solares, impedindo assim, a germinação e o desenvolvimento das plantas invasoras (Voll et al., 2004; Tesio et al., 2010).

Tabela 2. Massa seca $\left(\mathrm{kg} \mathrm{ha}^{-1}\right)$ de resíduos de buva, amargoso e buva + amargoso ao final de cinco anos de cultivo em área com variação no cultivo de milho solteiro e consórcio milho-braquiária. Ponta Porã, MS, 2017.

\begin{tabular}{lccc}
\hline \multicolumn{1}{c}{ Tratamentos } & Buva & Amargoso & Buva + Amargoso \\
\hline Milho solteiro de 2011 a 2015 & $1.181 \mathrm{a}$ & $1.335 \mathrm{a}$ & $2.516 \mathrm{a}$ \\
Consórcio em 2011 + milho solteiro de 2012 a 2015 & $467 \mathrm{~b}$ & $1.796 \mathrm{a}$ & $2.263 \mathrm{a}$ \\
Consórcio em 2011 e 2012 + milho solteiro de 2013 a 2015 & $1.058 \mathrm{a}$ & $1.400 \mathrm{a}$ & $2.458 \mathrm{a}$ \\
Consórcio de 2011 a 2013 + milho solteiro em 2014 e 2015 & $1.168 \mathrm{a}$ & $215 \mathrm{~b}$ & $1.383 \mathrm{~b}$ \\
Consórcio de 2011 a 2014 + milho solteiro em 2015 & $523 \mathrm{~b}$ & $0 \mathrm{~b}$ & $523 \mathrm{c}$ \\
Consórcio de 2011 a 2015 & $0 \mathrm{c}$ & $0 \mathrm{~b}$ & $0 \mathrm{~d}$ \\
Milho solteiro em 2011 + consórcio de 2012 a 2015 & $0 \mathrm{c}$ & $0 \mathrm{~b}$ & $0 \mathrm{~d}$ \\
Milho solteiro em 2011 e 2012 + consórcio de 2013 a 2015 & $0 \mathrm{c}$ & $0 \mathrm{~b}$ & $0 \mathrm{~d}$ \\
Milho solteiro de 2011 a 2013 + consórcio em 2014 e 2015 & $0 \mathrm{c}$ & $0 \mathrm{~b}$ & $0 \mathrm{~d}$ \\
Milho solteiro de 2011 a 2014 + consórcio em 2015 & $0 \mathrm{c}$ & $0 \mathrm{~b}$ & $0 \mathrm{~d}$ \\
\hline C.V.\% & 55,92 & 51,98 & 50,12 \\
\hline
\end{tabular}

Médias seguidas pela mesma letra não diferem entre si pelo teste de Scott-Knott a 5\% de probabilidade.

Tabela 3. Densidade (número de plantas $\mathrm{ha}^{-1}$ ) de buva, capim amargoso e plantas daninhas totais ao final de cinco anos de cultivo em área com variação no cultivo de milho solteiro e consórcio milho-braquiária. Ponta Porã, MS, 2017.

\begin{tabular}{|c|c|c|c|}
\hline Tratamentos & Buva & Amargoso & Buva + Amargoso \\
\hline Milho solteiro de 2011 a 2015 & $220.000 \mathrm{~b}$ & $60.000 \mathrm{a}$ & $280.000 \mathrm{a}$ \\
\hline Consórcio em 2011 + milho solteiro de 2012 a 2015 & $120.000 \mathrm{c}$ & $60.000 \mathrm{a}$ & $180.000 \mathrm{~b}$ \\
\hline Consórcio em 2011 e 2012 + milho solteiro de 2013 a 2015 & $290.000 \mathrm{a}$ & $40.000 \mathrm{~b}$ & $330.000 \mathrm{a}$ \\
\hline Consórcio de 2011 a 2013 + milho solteiro em 2014 e 2015 & $320.000 \mathrm{a}$ & $20.000 \mathrm{c}$ & $340.000 \mathrm{a}$ \\
\hline Consórcio de 2011 a 2014 + milho solteiro em 2015 & $110.000 \mathrm{c}$ & $0 \mathrm{c}$ & $110.000 \mathrm{c}$ \\
\hline Consórcio de 2011 a 2015 & $0 \mathrm{~d}$ & $0 \mathrm{c}$ & $0 \mathrm{~d}$ \\
\hline Milho solteiro em 2011 + consórcio de 2012 a 2015 & $0 \mathrm{~d}$ & $0 \mathrm{c}$ & $0 \mathrm{~d}$ \\
\hline Milho solteiro em 2011 e 2012 + consórcio de 2013 a 2015 & $0 \mathrm{~d}$ & $0 \mathrm{c}$ & $0 \mathrm{~d}$ \\
\hline Milho solteiro de 2011 a 2013 + consórcio em 2014 e 2015 & $0 \mathrm{~d}$ & $0 \mathrm{c}$ & $0 \mathrm{~d}$ \\
\hline Milho solteiro de 2011 a 2014 + consórcio em 2015 & $0 \mathrm{~d}$ & $0 \mathrm{c}$ & $0 \mathrm{~d}$ \\
\hline C.V. $(\%)$ & 41,59 & 42,83 & 41,97 \\
\hline
\end{tabular}

Médias seguidas pela mesma letra não diferem entre si pelo teste de Scott-Knott a 5\% de probabilidade.

Em todos os tratamentos que apresentavam milho solteiro em 2015 (milho solteiro de 2011 a 2015, consórcio em 2011 + milho solteiro de 2012 a 2015 , consórcio em 2011 e 2012 + milho solteiro de 2013 a 2015, consórcio de 2011 a 2013 + milho solteiro em 2014 e 2015 e consórcio de 2011 a 2014 + milho solteiro em 2015) houve presença de plantas daninhas. Dentre esses, o tratamento consorciado de 2011 a 2014 (consórcio de 2011 a 2014 + milho solteiro em 2015), foi o que apresentou as menores quantidades de massa seca $\left(523 \mathrm{~kg} \mathrm{ha}^{-1}\right)$ e número de plantas (110.000 plantas $\mathrm{ha}^{-1}$ ), do total de plantas daninhas (buva + amargoso), sendo que estavam representadas apenas pela buva, já que nesse tratamento houve ausência de amargoso (Tabelas 2 e 3).

As maiores quantidades de massa seca de buva foram observadas nos tratamentos milho solteiro de 2011 a 2015, consórcio em 2011 e 2012 + milho solteiro de 2013 a 2015 e consórcio de 2011 a 2013 + milho solteiro em 2014 e 2015. As maiores médias de massa seca de amargoso e buva + amargoso foram observadas nos tratamentos milho solteiro de 2011 a 2015, 
consórcio em 2011 + milho solteiro de 2012 a 2015 e consórcio em 2011 e 2012 + milho solteiro de 2013 a 2015 (Tabela 2).

Os tratamentos consórcio em 2011 e $2012+$ milho solteiro de 2013 a 2015 e consórcio de 2011 a $2013+$ milho solteiro em 2014 e 2015 apresentaram maiores número de plantas ha ${ }^{-1}$ de buva e buva + amargoso, sendo que para buva + amargoso o tratamento milho solteiro de 2011 a 2015 também apresentou maiores quantidades. Para o amargoso as maiores médias foram observadas nos tratamentos milho solteiro de 2011 a 2015 e consórcio em 2011 + milho solteiro de 2012 a 2015 (Tabela 3). A predominância das espécies de buva e amargoso se deve ao uso contínuo de gliphosate, utilizado para eliminar a forrageira nos tratamentos sem braquiária e para dessecação de pré-plantio da soja, além da utilização de atrazine. Dessa forma, houve controle sobre as demais espécies de plantas daninhas, exceto buva e amargoso, que são consideradas espécies de difícil controle. Esses resultados mostram a capacidade da braquiária em atuar como um método alternativo no controle de plantas invasoras, diminuindo a infestação das mesmas, mesmo após um ano do seu cultivo, como no caso do tratamento consórcio de 2011 a 2014 + milho solteiro em 2015. Evidenciam também, a capacidade de reinfestação da buva após um ano (consórcio de 2011 a 2014 + milho solteiro em 2015) e de amargoso após dois anos (consórcio de 2011 a 2013 + milho solteiro em 2014 e 2015) em que se cessa o cultivo de consórcio na área, ou seja, quando se tem um consórcio já bem estabelecido na área ao longo dos anos, ao realizar o cultivo de milho solteiro no ano seguinte, a buva reaparece na área, enquanto o amargoso só reaparece no segundo ano com cultivo de milho solteiro.

A buva (Coniza bonariensis) é uma planta fotoblástica positiva, sendo necessário a incidência de luz na semente para sua germinação. Dessa forma, um dos principais métodos de controle é o uso de milho consorciado com braquiária, onde a massa formada pelo capim irá reduzir a incidência de luz nas sementes e, consequentemente, reduzir a germinação das mesmas. Além de impedir o crescimento das plântulas devido ao maior sombreamento. Para a espécie Digitaria insularis (capim amargoso), que não necessita de luz para a germinação das sementes (MONDO et al., 2010), o controle está associado a supressão da braquiária sobre as plantas de amargoso ou então a um possível efeito alelopático.

Analisando o tratamento consórcio de 2011 a $2014+$ milho solteiro em 2015 como sendo o primeiro ano de cultivo de milho solteiro em sucessão à soja, há a presença de plantas daninhas em baixas quantidades, com o aumento da infestação no decorrer dos anos de monocultivo, sendo que, após cinco anos de sucessão soja-milho solteiro (milho solteiro de 2011 a 2015) é observado um aumento de $1.993 \mathrm{~kg} \mathrm{ha}^{-1}$ de massa seca de plantas daninhas em relação ao primeiro ano de cultivo (Tabelas 2 e 3). Por outro lado, a partir do primeiro ano de cultivo consorciado após anos de sucessão soja-milho safrinha (milho solteiro de 2011 a 2014 + consórcio em 2015), há o controle total das plantas daninhas.

Concenço et al. (2013) também observaram que a infestação por plantas daninhas é maior nos sistemas em que não se utiliza a braquiária no outono-inverno, havendo o aumento do banco de sementes ao longo dos anos de monocultivo. Por outro lado, a semeadura de braquiária em sucessão à soja, pelo período de três anos, sendo solteira ou consorciada com milho, foi capaz de manter o nível de infestação por plantas daninhas próximo ao observado no início do monocultivo da soja.

\section{Conclusões}

O consórcio milho-braquiária aumenta a massa total de resíduos e inibe a presença de plantas daninhas de difícil controle no ano de seu cultivo.

A reinfestação por buva ocorre após um ano sem consórcio e de capim amargoso após dois anos sem consórcio, porém em menores quantidades do que na sucessão soja-milho safrinha.

\section{Referências Bibliográficas}

Andrade, F. H., 1995. Analysis of growth and yield of maize, sunflower and soybean grown at Balcarce, Argentina. Field Crops Research, 41, 1-12.

Ceccon, G.; Staut, L. A.; Sagrilo, E.; Machado, L. A. Z.; Nunes, D. P.; Alves, V. B., 2012. Legumes and forage species sole or intercropped with corn in soybeancorn succession in midwestern brazil. Revista Brasileira de Ciências do Solo, 37, 204-212.

CEMTEC. Centro de monitoramento de tempo, do clima e dos recursos hídricos de Mato Grosso do Sul, 2018. Banco de Dados. <http://www.cemtec.ms.gov.br/> (acessado 15 de maio de 2018).

Concenço, G.; Salton, J. C.; Brevilieri, R. C.; Mendes, P. B.; Secretti, M. L., 2011. Soil seed bank of plant species as a function of longterm soil management and sampled depth. Planta Daninha, 29, 725-736.

Concenço, G.; Ceccon, G.; Correia, I. V. T.; Leite, L. F.; Alves, V. B., 2013. Ocorrência de espécies daninhas em função de sucessões de cultivo. Planta Daninha, 31, 359-368.

EMBRAPA. Empresa brasileira de pesquisa agropecuária, 2016. Guia Clima. Agropecuária Oeste. <http://clima.cpao.embrapa.br> (acessado 22 de outubro de 2017).

Malty, J. dos S.; Siqueira, J. O.; Moreira, F. M. de S., 2006. Efeitos do glifosato sobre microrganismos simbiotróficos de soja, em meio de cultura e casa de vegetação. Pesquisa Agropecuária Brasileira, 41, 285-291.

Mondo, V. H. V.; Carvalho, S. J. P.; Dias, A. C. R.; Marcos Filho, J., 2010. Efeitos da luz e temperatura na germinação de sementes de quatro espécies de plantas daninhas do gênero Digitaria. Revista Brasileira de Sementes, 32, 131-137. 
Santos, H. G.; Jacomine, P. K. T.; Anjos, L. H. C.; Oliveira, V. A.; Lumbreras, J. F.; Coelho, M. R.; Almeida, J. A.; Cunha, T. J. F.; Oliveira, J. B., 2013. Sistema brasileiro de classificação de solos, terceira ed. Embrapa Solos, Rio de Janeiro.

Silva, D. A.; Souza, L. C. F.; Vitorino, A. C. T.; Gonçalves, M. C., 2011. Aporte de fitomassa pelas sucessões de culturas e sua influência em atributos físicos do solo no sistema plantio direto. Bragantia, 70, 147-156.
Tesio, F.; Weston, L. A.; Vidotto, F.; Ferrero, A., 2010. Potential allelopathic effects of Jerusalem Articho ke (Helianthus tuberosus) leaf tissues. Weed Technology, 24, 378-385.

Voll, E.; Franchini, J. C.; Cruz, R. T.; Gazziero, D. L. P.; Brighenti, A. M.; Adegas, F. S., 2004. Chemical interactions of Brachiaria plantaginea with Commelina benghalensis and Acanthospermum hispidum in soybean cropping systems. Journal of Chemical Ecology, 30, 1467-1475. 